\title{
Characterization of the effects of heat stress on autophagy induction in the pig oocyte
}

Benjamin J. Hale, Yunsheng Li, Malavika K. Adur, Aileen F. Keating, Lance H. Baumgard and Jason W. Ross* (1)

\begin{abstract}
Background: Heat stress (HS) occurs when body heat accumulation exceeds heat dissipation and is associated with swine seasonal infertility. HS contributes to compromised oocyte integrity and reduced embryo development. Autophagy is a potential mechanism for the oocyte to mitigate the detrimental effects of HS by recycling damaged cellular components.
\end{abstract}

Methods: To characterize the effect of HS on autophagy in oocyte maturation, we utilized an in vitro maturation (IVM) system where oocytes underwent thermal neutral (TN) conditions throughout the entire maturation period (TN/TN), HS conditions during the first half of IVM (HS/TN), or HS conditions during the second half of IVM (TN/HS).

Results: To determine the effect of HS on autophagy induction within the oocyte, we compared the relative abundance and localization of autophagy-related proteins. Heat stress treatment affected the abundance of two well described markers of autophagy induction: autophagy related gene 12 (ATG12) in complex with ATG5 and the cleaved form of microtubule-associated protein 1 light chain 3 beta (LC3B-II). The HS/TN IVM treatment increased the abundance of the ATG12-ATG5 complex and exacerbated the loss of LC3B-II in oocytes. The B-cell lymphoma 2 like 1 protein (BCL2L1) can inhibit autophagy or apoptosis through its interaction with either beclin1 (BECN1) or $B C L 2$ associated $X$, apoptosis regulator $(B A X)$, respectively. We detected colocalization of BCL2L1 with BAX but not BCL2L1 with BECN1, suggesting that apoptosis is inhibited under the HS/TN treatment but not autophagy. Interestingly, low doses of the autophagy inducer, rapamycin, increased oocyte maturation.

Conclusions: Our results here suggest that HS increases autophagy induction in the oocyte during IVM, and that artificial induction of autophagy increases the maturation rate of oocytes during IVM. These data support autophagy as a potential mechanism activated in the oocyte during HS to recycle damaged cellular components and maintain developmental competence.

Keywords: Oocyte, Autophagy, Heat stress, Pig

\footnotetext{
*Correspondence: jwross@iastate.edu

Department of Animal Science, lowa State University, 2356 Kildee Hall, Ames, IA 50011, USA
} 


\section{Summary sentence}

Heat stress induces autophagy in the pig oocyte during oocyte maturation, and autophagy is a potential mechanism by which the oocyte mitigates cellular stress.

\section{Background}

Heat stress (HS) occurs when heat dissipation methods are exceeded by both internal and external heat accumulation [1, 2]. Attempts to maintain euthermia during HS leads to perturbations in physiological processes, such as reduced feed intake, blood flow redistribution to the periphery, and endocrine changes. Collectively these adaptations reduce growth performance, reproductive ability, and alter body composition [3, 4]. These detrimental effects of HS create a financial burden on swine producers and animal agriculture in general. Almost two decades ago, St. Pierre et al. [5] predicted that the combined effects of HS accounted for an approximately $\$ 2$ billion loss in United States livestock industries. In addition, the economic burden of HS on the United States swine industry alone has been estimated to be $\$ 900$ million per year [6].

A large portion of the financial burden caused by HS can be explained by a decrease in reproductive efficiency [4]. HS reduces oocyte developmental competence, and induces apoptosis in in vitro fertilized and parthenogenetically activated porcine embryos [7-9]. Oocyte meiotic competence appears to be particularly sensitive to HS, as both pig and bovine oocytes halt meiotic resumption under HS $[10,11]$. Furthermore, HS has been shown to impair the gap junctions between oocytes and the surrounding cumulus cells [12, 13]. For oocytes to remain viable, a mechanism is required to maintain homeostasis and mitigate deleterious effects.

Autophagy is a potential stress mitigation response, as it is the process by which damaged cellular components are recycled. There are three major types of autophagy: chaperone-mediated autophagy, microautophagy, and macroautophagy. Macroautophagy (referred to hereafter as autophagy) accounts for the largest amount of cellular resource recycling of the three different types [14]. Autophagy is the sequestration of cytoplasm into a doublemembraned cytosolic vesicle, the autophagosome, that fuses with a lysosome to form an autolysosome for degradation by lysosomal hydrolases [15]. The steps of autophagy can be broken down into induction, autophagosome formation, autophagosome-lysosome fusion, and degradation [16]. These processes are marked by the formation of large protein complexes, and much of the regulation occurs post-translationally $[17,18]$.

During autophagy, Beclin 1 (BECN1) plays a key role in sequestering the nascent lipid membrane that will eventually form the autophagosome $[19,20]$. The extension of the autophagosomal membrane around targeted cell debris occurs through two different pathways: One pathway includes the formation of the Autophagy related (ATG)12-ATG5-ATG16 complex, where ATG7 acts like an E1-activating enzyme to conjugate ATG12 to ATG5 [21, 22]. The second ubiquitin-like conjugation pathway results in the cleavage of microtubuleassociated proteins 1 light chain 3 alpha/beta (LC3A/B), exposing a glycine residue at the $\mathrm{C}$-terminal end. This process results in the conjugation of LC3 with phosphatidylethanolamine (PE), ultimately forming LC3-II [23], which is a well described marker of mammalian autophagy $[24,25]$.

Autophagy and apoptosis are regulated in tight coordination, partly through B-cell lymphoma 2 (BCL2) family member proteins, important regulators of apoptosis during mammalian ovary development [26-30]. The dual role of BCL2 family members to regulate both autophagy and apoptosis is mediated by the ability of BCL2 and BCL2 like 1 (BCL2L1; also known as BCL-XL) to prevent apoptosis by inhibiting the formation of mitochondrial pores that release cytochrome $\mathrm{C}$, via interaction with BCL2 associated X, apoptosis regulator (BAX) [31], while BCL2 and BCL2L1 can also interact with BECN1 to regulate autophagy [32, 33].

Both basal and stress-induced autophagy have been observed in the embryo and oocyte. Deficiencies in autophagy-related genes negatively affect both early and late stage embryonic development [34-37] and embryos can also respond to external stressors by inducing autophagy [38, 39]. In the oocyte, autophagy related gene 5 (Atg5) knock-out mice fail to develop past the 4-cell embryonic stage [40]. Furthermore, LC3-II is detectable during initial culture of pig oocytes [41], and BECN1 has been observed in the mouse oocyte [42].

Autophagy represents a potential molecular mechanism by which the oocyte could mitigate the detrimental effects of HS. We have previously utilized an in vivo model to demonstrate that HS affects autophagy-related proteins in the pig ovary, increases the abundance of autophagosome-like structures in follicles, as well as increases BCL2L1 in the ovary [43]. Our working hypothesis is that HS upregulates the autophagy pathway in the oocyte, and thus our study objective was to characterize the induction of autophagy in response to HS during in vitro maturation.

\section{Methods}

\section{In vitro maturation}

Pig ovaries were obtained from a local abattoir for isolation of cumulus-oocyte-complexes (COCs) to be subjected to in vitro maturation (IVM) [44, 45]. Briefly, follicles $(2-4 \mathrm{~mm})$ were aspirated and COCs were collected and washed in TL-Hepes with $0.1 \%$ polyvinyl alcohol (PVA). Cumulus oocyte complexes were cultured 
in maturation media (Tissue Culture Media 199 (TCM199)) containing $0.57 \mathrm{mM} \mathrm{L}$-cysteine, follicle stimulating hormone $(0.5 \mu \mathrm{g} / \mathrm{mL})$, luteinizing hormone $(0.5 \mu \mathrm{g} / \mathrm{mL})$, and epidermal growth factor $(10 \mathrm{ng} / \mathrm{mL})$ for approximately $42 \mathrm{~h}$ at $38.5{ }^{\circ} \mathrm{C}$ in $5 \% \mathrm{CO}_{2}$. Prior to IVM, a representative sample of germinal vesicle-intact (GV) stage oocytes for each replication were randomly selected from the COC pool. Identification of polar body was performed with phase-contrast light microscopy. Oocytes used for analysis were stripped of cumulus cells via gentle vortex (6 to $8 \mathrm{~min}$ ) in 1\% hyaluronidase in TLHepes-PVA and washed in TL-Hepes-PVA. To observe the effect of HS on IVM of oocytes, oocytes underwent three different IVM temperature treatments: 1$)$ TN conditions $\left(38.5^{\circ} \mathrm{C}\right)$ for the entirety of $\left.42 \mathrm{~h}(\mathrm{TN} / \mathrm{TN}), 2\right) \mathrm{TN}$ conditions for the first $21 \mathrm{~h}$ of IVM followed by HS $\left(41{ }^{\circ} \mathrm{C}\right)$ conditions for the following $21 \mathrm{~h}(\mathrm{TN} / \mathrm{HS})$, or 3 ) HS conditions for the first $21 \mathrm{~h}$ of IVM followed by TN conditions for the following $21 \mathrm{~h}$ (HS/TN). Following IVM oocytes were stripped of cumulus cells by vortexing 5-6 min in TL-Hepes-PVA supplemented with $1 \%$ hyaluronidase and washed in TL-Hepes-PVA.

To characterize the temporal change in abundance of LC3B-II, oocytes were matured under either the TN/TN or HS/TN treatments. A pool of oocytes was collected before introduction into maturation media $(0-\mathrm{h})$. Oocytes were collected after $21 \mathrm{~h}$ of either TN (21-h TN) or HS conditions (21-h HS). The remainder of the oocytes that had experienced $21 \mathrm{~h}$ of TN conditions were allowed to continue maturation under TN conditions for a total of $42 \mathrm{~h}(42-\mathrm{h} \mathrm{TN} / \mathrm{TN})$, and the remainder of the oocytes that had experienced $21 \mathrm{~h}$ of HS conditions continued maturation under a subsequent $21 \mathrm{~h}$ of TN conditions, for a total of $42 \mathrm{~h}$ (42-h HS/TN).

\section{Western blot analysis}

Pools of 50 denuded oocytes per replicate were collected as described above after 21 or $42 \mathrm{~h}$ of IVM. Oocyte pools were lysed in $5 \mu \mathrm{L}$ of Laemmli sodium dodecyl sulfate buffer at $95^{\circ} \mathrm{C}$ for $4 \mathrm{~min}$ followed by $1 \mathrm{~min}$ on ice and then centrifugation at $1000 \mathrm{rpm}$ for $1 \mathrm{~min}$ at room temperature. Lysates from fifty oocytes were loaded per lane of a 4-20\% Tris glycine gel (Lonza PAGEr Gold Precast Gels). The BioRad Mini PROTEAN Tetra System was used to separate protein homogenates at $60 \mathrm{~V}$ for $30 \mathrm{~min}$ followed by $120 \mathrm{~V}$ for $90 \mathrm{~min}$. The protein was transferred to a nitrocellulose membrane for $1 \mathrm{~h}$ at $100 \mathrm{~V}$ at $4{ }^{\circ} \mathrm{C}$. Membrane blocking was conducted using $5 \%$ milk in phosphate buffered solution with $0.5 \%$ Tween 20 (PBST) for $1 \mathrm{~h}$ at room temperature. A rabbit antiBECN1 (Cell Signaling Technology, 3495), rabbit antiLC3B (Cell Signaling Technology, 3868), rabbit antiATG12 (Cell Signaling Technology, 4181), rabbit antiBCL2L1 (Cell Signaling Technology, 2764), or normal rabbit IgG (Cell Signaling Technology, 2729) as a negative control were added (1:1000 dilution) to the membrane in $0.5 \%$ milk in PBS overnight at $4{ }^{\circ} \mathrm{C}$. Following primary antibody incubation, the membranes were washed with PBST (PBS with 0.1\% Tween) three times at room temperature for $10 \mathrm{~min}$ each. Donkey antiRabbit IgG (Amersham ECL NA934) was incubated (1: 1000) with the membrane for $1 \mathrm{~h}$ at room temperature. The membrane was then washed three times for $10 \mathrm{~min}$ each at room temperature. Horseradish peroxidase substrate (Millipore, Billerica, MA) was added to the membrane for $1 \mathrm{~min}$ in the dark, and was exposed to $\mathrm{x}$-ray film and developed for visualization. Average pixel intensity for the band corresponding to the primary antibody was compared for each blot using Image Studio Lite (LiCore). Signal from detection of each protein of interest was normalized to $\alpha$-tubulin.

\section{Rapamycin oocyte IVM and activation}

Cumulus-oocyte-complexes were collected and subjected to IVM under the HS/TN treatment as mentioned above, with the addition of either DMSO vehicle control, $1.0 \mathrm{nM}$ rapamycin, $10 \mathrm{nM}$ rapamycin, or $100 \mathrm{nM}$ rapamycin. In addition to rapamycin, IVM media for this study contained $10 \mathrm{ng} / \mathrm{mL}$ leukemia inhibitory factor (LIF; Sigma-Aldrich L5283), $40 \mathrm{ng} / \mathrm{mL}$ basic fibroblast growth factor (Sigma-Aldrich F0291), and $20 \mathrm{ng} / \mathrm{mL}$ insulin-like growth factor 1 (Sigma-Aldrich I36769). After $21 \mathrm{~h}$ of HS IVM followed by a subsequent $21 \mathrm{~h}$ of TN IVM, oocytes were denuded and healthy metaphase II oocytes containing extruded polar bodies were counted as a percent of total oocytes per treatment. Pools of 50 metaphase II arrested oocytes were then flash frozen in liquid nitrogen to be used for downstream analysis.

\section{Oocyte fixation and immunohistochemistry}

Oocytes were collected and denuded, as described above, from different time points during IVM and then fixed and mounted to slides as previously described [46, 47]. Briefly, oocytes were fixed in $4 \%$ paraformaldehyde in PBS overnight at $4{ }^{\circ} \mathrm{C}$, and then transferred to $70 \%$ ethanol in PBS at $4{ }^{\circ} \mathrm{C}$. Oocytes were permeabilized in $0.5 \%$ Triton X$100^{\text {mix }}$ (Sigma-Aldrich, St. Louis, MO) for $30 \mathrm{~min}$ at room temperature. Next, oocytes were blocked in $5 \%$ bovine serum albumin (Sigma-Aldrich, St. Louis, MO) for $45 \mathrm{~min}$ at room temperature, then incubated with primary antibody overnight at $4{ }^{\circ} \mathrm{C}$. After approximately $24 \mathrm{~h}$, oocytes were washed twice in PBS for $30 \mathrm{~min}$, and incubated with secondary antibody for $1 \mathrm{~h}$ at room temperature. The oocytes were then washed twice in PBS for $30 \mathrm{~min}$, and mounted to microscope slides using SlowFade Gold Mountant containing DAPI (S36939, ThermoFisher Scientific, Pittsburgh, Pennsylvania). 


\section{Colocalization of autophagy markers}

To label proteins of interest for colocalization, rabbit anti-BCL2L1 (Cell Signaling Technology, 2764S), rabbit anti-BECN1 (Cell Signaling Technology, 3495S), mouse anti-BCL2L1 (Novus $\left.{ }^{\mathrm{rm}}, 46,569\right)$, and mouse anti-BAX (Novus, 28,566) primary antibodies were used at a 1:200 dilution. Secondary antibodies used were anti-mouse IgG AlexaFluor 647 (Cell Signaling Technology, 4410S) and anti-rabbit IgG FITC (Life Technologies, F2765) at a 1:250 dilution. To control for nonspecific binding of primary antibodies, a pool of oocytes was incubated in normal rabbit IgG (Cell Signaling Technology, 2729) and normal mouse IgG (Cell Signaling Technology, 5415) at a 1:200 dilution instead of primary antibodies. A Leica SP5X MP confocal microscope (Exton, PA) was used to image antibody labeled proteins of interest.

Primary antibodies derived from different species were used so that secondary antibodies with different fluorophores would recognize and bind to the separate primary antibodies within the same fixed oocyte. This made it possible to view two different fluorophores conjugated to secondary antibodies at different excitation wavelengths. 30 oocytes per temperature treatment per time point were visually assessed using a confocal microscope. Three oocytes per temperature treatment per time point of IVM were used in colocalization analysis on sequential focal planes (step size of $1 \mu \mathrm{m}$ ) measuring spatial fluorescence over approximately $50 \mu \mathrm{m}$ of each oocyte. Fluorescence of DAPI stained chromatin, labeled rabbit anti-BCL2L1 and mouse anti-BAX, or labeled rabbit anti-BECN1 and mouse anti-BCL2L1 was measured.

\section{Statistical analysis}

Statistical analysis of maturation rate, western blot data, and co-fluorescence data was conducted using PROC MIXED in SAS Enterprise Miner Workstation version 14.1 (Carry, NC), where a standard student ttest was used to compare statistical differences.
Statistical significance was determined when $P$ values were less than or equal to 0.05 . The PDC colocalization plugin [48] in the Image processing program [49] was used to calculate Pearson's and Spearman's correlation coefficient and scatter plots representing colocalization of signal intensity collected from confocal microscopy of individual oocytes. Corresponding z-stacks with blocks of pixels randomly scrambled were used to determine that the probability of the measured value for Pearson's or Spearman's correlation between two color channels was significantly greater than would be calculated if there was only random overlap of the same information.

\section{Results}

Heat stress decreases oocyte maturation rate

To characterize the effect of HS on maturation, oocytes underwent IVM during one of three temperature treatments: TN conditions throughout the entire 42-h maturation period (TN/TN), HS conditions during the second half of IVM (TN/HS), or HS conditions during the first half of IVM (HS/TN). Oocytes were subject to 21-h HS intervals because we have previously observed that $42 \mathrm{~h}$ of HS greatly decreases oocyte maturation and subsequent embryo development [50]. This also allowed us to compare maturation rate of different temperature treatments with downstream protein abundance and localization. Both HS treatments decreased maturation compared to TN/TN control, where the maturation rate of TN/TN oocytes was $66.9 \pm 5.0 \%$, the maturation rate of TN/HS oocytes was decreased to $44.9 \% \pm 5.0 \%(P<$ 0.01 ), and the maturation rate of HS/TN oocytes was decreased to $33.2 \pm 1.6 \%(P<0.01$; Table 1$)$. The maturation rate of $\mathrm{HS} / \mathrm{TN}$ oocytes decreased compared to the maturation rate of TN/HS $(P \leq 0.05$; Table 1$)$. These are comparable to previous results from our group [50].

\section{Heat stress affects autophagy-related proteins}

The abundance of BECN1, fomation of the ATG12ATG5 complex, and the cleavage of LC3B was measured via western blotting to characterize the effect of $\mathrm{HS}$ on

Table 1 Oocyte maturation to MII arrest under different temperature treatments

\begin{tabular}{ccc} 
Treatment Group $^{1}$ & $\begin{array}{c}\text { Total Oocytes } \\
\text { Matured }^{2}\end{array}$ & $\begin{array}{c}\text { Percentage MII } \\
\text { Arrested Oocytes }^{3}\end{array}$ \\
\hline TN/TN & 269 & $67 \% \pm 5.0^{\mathrm{a}}$ \\
HS/TN & 242 & $33 \% \pm 1.6^{\mathrm{c}}$ \\
TN/HS & 315 & $44 \% \pm 5.0^{\mathrm{b}}$ \\
\hline
\end{tabular}

${ }^{1}$ Temperature treatment oocytes experienced during IVM: TN throughout the entire IVM (TN/TN) or HS during the first half (HS/TN) or second half (TN/HS) of IVM.

${ }^{2}$ Total number of GV oocytes matured for each treatment from four replicates.

${ }^{3}$ Percentage of MIl arrested oocytes from each treatment. Mean \pm SEM.

$\mathrm{a}, \mathrm{b}, \mathrm{c}$ Values with different superscripts in the same column are significantly different $(P<0.05)$. 
autophagy induction in the oocyte. The abundance of BECN1 and BCL2 like 1 (BCL2L1) were unaffected by temperature treatment (Fig. $1 \mathrm{~A}$ and $\mathrm{B}$ ). The abundance of ATG12 in complex with ATG5 was increased in oocytes collected after $42 \mathrm{~h}$ of IVM of each temperature treatment (TN/TN, TN/HS, or HS/TN) compared to GV-intact oocytes collected before IVM. There was increased abundance $(\sim 1.5$ fold; $P<0.01)$ of ATG12 in complex with ATG5 after $42 \mathrm{~h}$ of IVM under the HS/
TN temperature treatment compared to the TN/TN $(P<0.01)$ and TN/HS $(P<0.01$; Fig. $1 \mathrm{~A}$ and $\mathrm{B})$.

There was no effect of temperature treatment on the abundance of LC3B II in oocytes after IVM with any of the three temperature treatments $(P>0.05)$. Although, there was decreased LC3B-II in TN/TN $(P<0.01)$, TN/HS $(P<0.01)$ and HS/TN oocytes $(P<$ $0.01)$ compared to oocytes collected at $0 \mathrm{~h}$ of IVM (Fig. 1A and B). Compared to oocytes collected at 0-

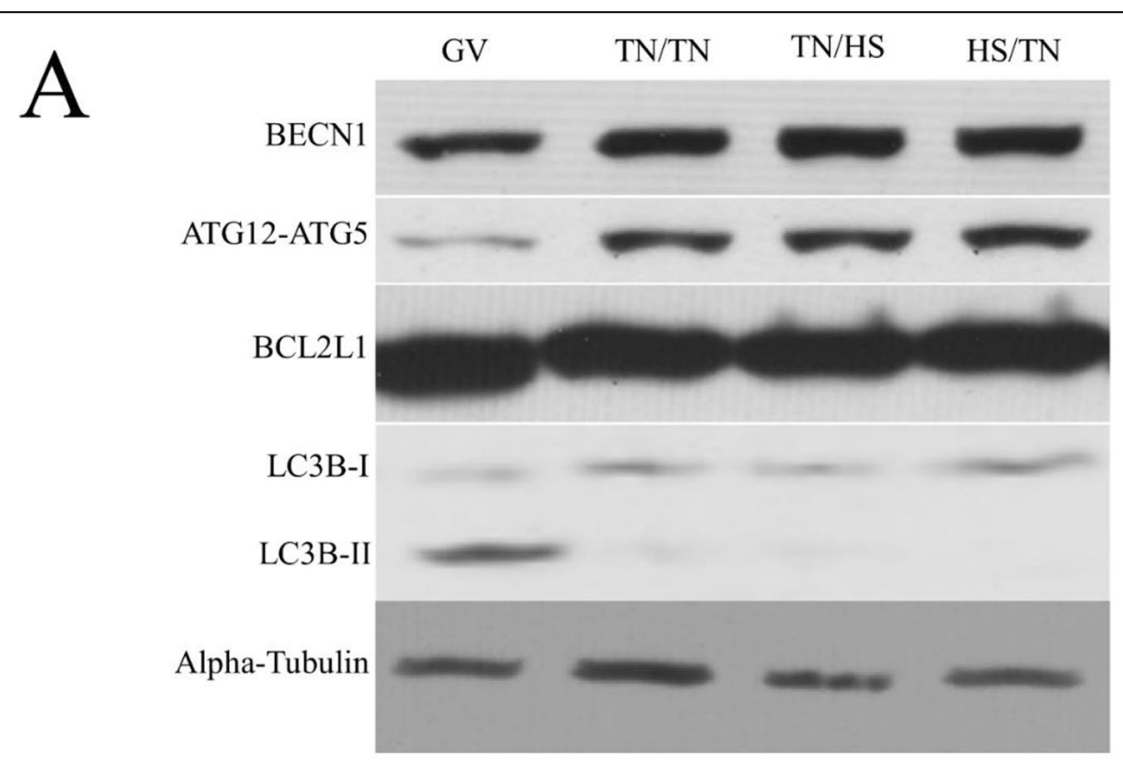

$\mathrm{B}$

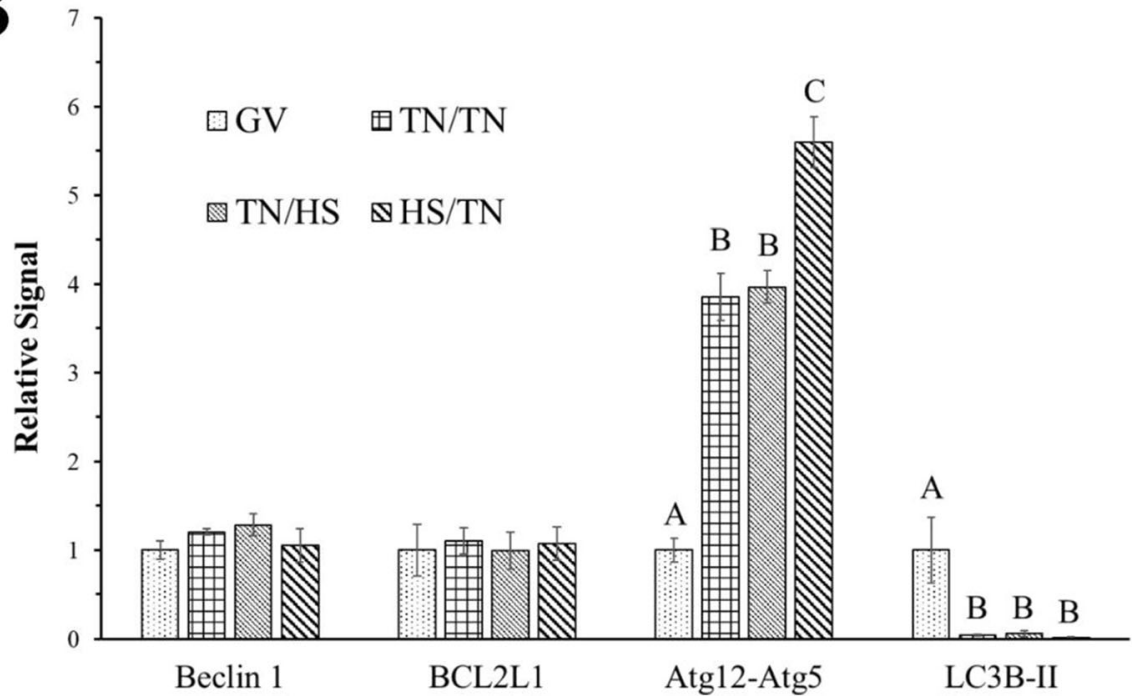

Fig. 1 Heat stress during the first half of IVM increases the abundance of ATG12 in complex with ATG5. Oocytes collected from aspirated pig follicular fluid underwent in vitro maturation (IVM) in either TN conditions throughout the entire 42-h maturation period (TN/TN), HS conditions during the second half of IVM (TN/HS), or HS conditions during the first half of IVM (HS/TN). Representative western blots for BECN1, ATG12-ATG5 complex, BCL2L1, LC3B, and a-tubulin (A) from oocytes collected before IVM (GV) and after $42 \mathrm{~h}$ of IVM. There was increased abundance of ATG12 in complex with ATG5 after $42 \mathrm{~h}$ of IVM under the HS/TN temperature treatment compared to the TN/TN and TN/HS (B). Different superscripts within the same protein denotes significant difference $(P<0.05)$ 
h, there was an approximately 24-fold lower abundance of LC3B-II in oocytes collected after TN/TN IVM, approximately 17-fold lower abundance in oocytes collected after TN/HS IVM, and approximately 73-fold lower abundance of LC3B-II in oocytes collected after HS/TN IVM (Fig. 1A and B).

The observed sharp decrease in LC3B-II due to temperature treatment provided rationale for an IVM experiment in which oocytes were collected after $21 \mathrm{~h}$ to determine the temporal effects of HS on LC3B-II. Although the abundance of LC3B-II did not differ between TN/TN oocytes and HS/TN oocytes at $42 \mathrm{~h}$ of IVM $(P=0.92)$, there was decreased abundance of LC3B-II after $21 \mathrm{~h}$ of HS $(0.21 \pm 0.6$ relative band intensity) compared to oocytes collected after $21 \mathrm{~h}$ of TN $(0.9 \pm 0.26 ; P<0.01$; Fig. 2A and B). These data suggest that HS affects the utilization of autophagy-related proteins in the oocyte.

\section{BCL2L1, BAX, and BECN1 interactions}

Because HS in the first half of IVM sharply decreased oocyte LC3B-II, the interaction of BCL2L1 with either $\mathrm{BAX}$ or BECN1 was determined to assess a potential HS-induced regulatory mechanism. The TN/HS treatment was not used in further experiments because it appeared to have a lesser affect on LC3B-II turnover. Oocytes that underwent IVM in either TN/TN or HS/ TN conditions were fixed for immunohistochemistry (IHC) to determine BCL2L1, BECN1, or BAX Co-

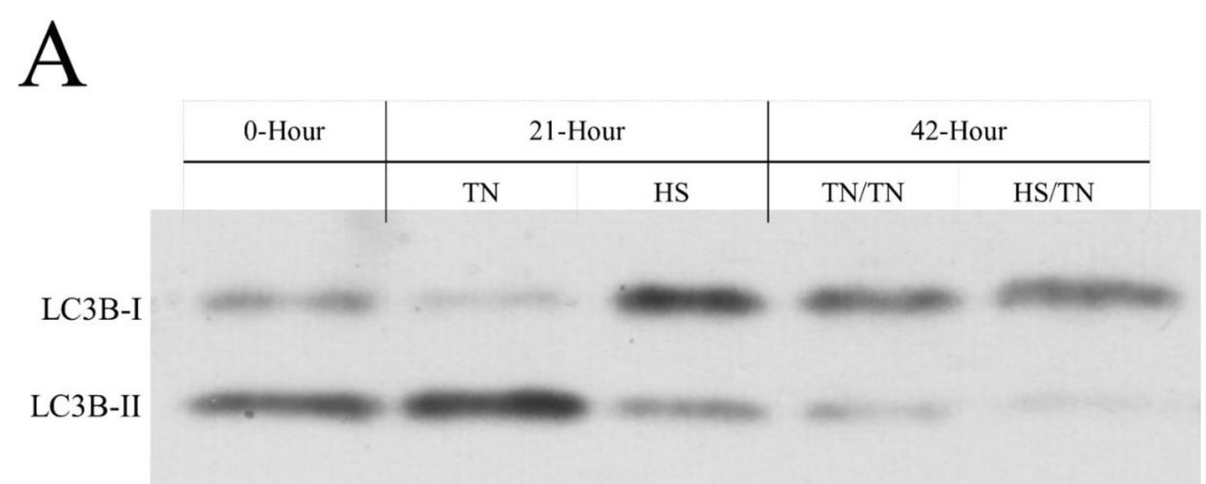

B

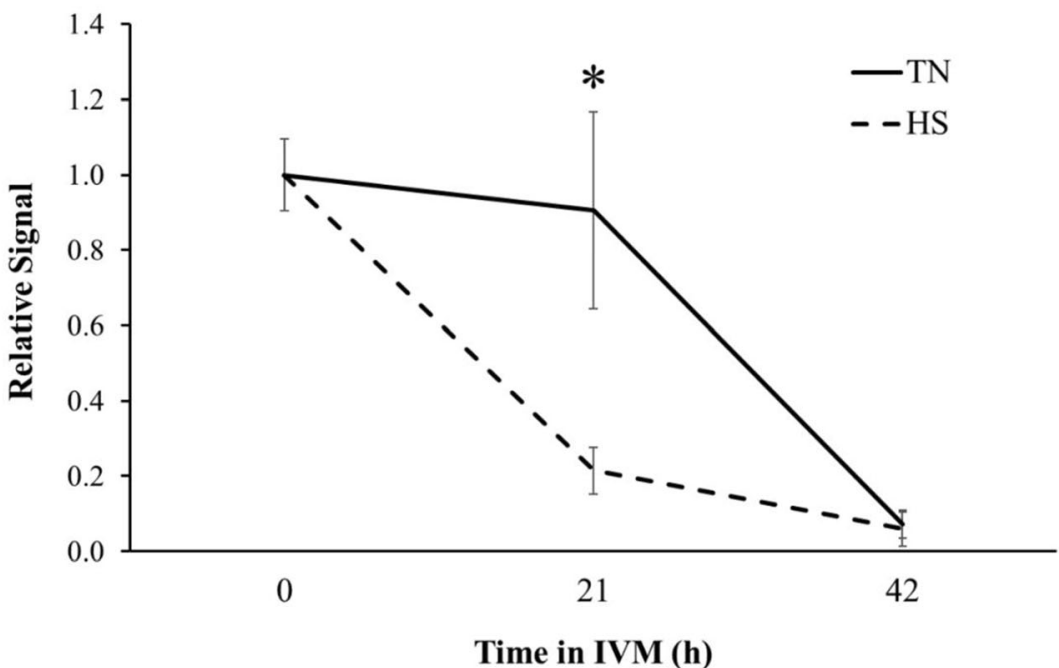

Fig. 2 Heat stress exacerbates the decrease of LC3B-II in the oocyte. Oocytes collected from aspirated pig follicular fluid underwent in vitro maturation (IVM) in either TN conditions throughout the entire $42 \mathrm{~h}$ maturation period or HS conditions during the first half of IVM (HS/TN). Representative western blot for LC3B from oocytes having undergone TN or HS conditions in IVM after 21 or $42 \mathrm{~h}$ or collected before IVM (A). There was decreased abundance of cleaved LC3B-II at $21 \mathrm{~h}$ of HS IVM compared with $21 \mathrm{~h}$ of TN IVM (B). Asterisks denotes significant difference $(P<0.05)$ from control 
localization. Based on the Pearson's $\left(r_{\mathrm{P}}\right)$ or Spearman's $\left(\mathrm{r}_{\mathrm{S}}\right)$ correlation coefficients, where a $r_{P}$ or $r_{S}$ closer to 1 is indicative of co-localization (Table 2) and overlap of fluorescent signal (Fig. 3A and $\mathrm{B}$ ), neither the time point nor the temperature treatment affected colocalization of BCL2L1 and BAX. Based on level of fluorescence, BAX was numerically increased, but not significantly increased, at $21 \mathrm{~h}$ of $\mathrm{HS}$ compared to TN conditions (Fig. S2B). There were no effects of time or temperature treatment on the abundance of BCL2L1 based on level of fluorescence (Fig. S2C).

Based on the $r_{P}$ and $r_{S}$ correlation coefficients (Table 2) and overlap of fluorescent signal (Fig. 4A and B), there was little colocalization of anti-BECN1 and anti-BCL2L1 antibodies regardless of time point during IVM or temperature treatment (Table 2). BECN1 staining appeared punctate at all time points and temperature treatment with no overlap with BCL2L1 staining (Fig. 4A and $B)$. There appeared to be more intense punctate BECN1 focal staining in oocytes (Fig. 4A and B). This data suggests that BCL2L1 is participating in the regulation of apoptosis in IVM oocytes under TN or HS conditions, while not appearing to inhibit autophagy.

\section{Low concentration of rapamycin increases maturation rate}

To determine if inducing autophagy in oocytes during HS increases the oocyte's ability to mature to MII arrest, oocytes underwent IVM while experiencing HS during the first $21 \mathrm{~h}$ and TN conditions the following $21 \mathrm{~h}$ in the presence of vehicle control, $100 \mathrm{nM}, 10 \mathrm{nM}$, or $1 \mathrm{nM}$ rapamycin. Oocytes treated with all four concentrations of rapamycin were subjected to the HS/TN IVM treatment, based upon the effect of this temperature treatment on ATG12-ATG5 complex and LC3B-II abundance. The maturation rate of oocytes in the presence of DMSO vehicle control was $50.0 \pm 4.1,43.6 \pm$ $5.6 \%$ for $100 \mathrm{nM}$ rapamycin, $47.8 \pm 5.5 \%$ for $10 \mathrm{nM}$ rapamycin, and $65.8 \pm 5.0 \%$ for $1 \mathrm{nM}$ rapamycin (Fig. 5). Including $100 \mathrm{nM}$ or $10 \mathrm{nM}$ rapamycin in the IVM media had no effect on maturation rate after HS/TN compared to vehicle control $(P=0.31$ and $P=0.72$, respectively), though oocytes matured in the presence of $1 \mathrm{nM}$ rapamycin had an approximately 1.3-fold increase in maturation rate compared to vehicle control $(P=0.03$; Fig. 5$)$. This data suggests low concentrations of rapamycin may provide the oocyte some resistance to HS and improve their ability to reach MII arrest, potentially through induction of autophagy.

\section{Discussion}

Autophagy is the process by which cellular components are recycled and is activated by a variety of stressors [51]. In autophagy, the autophagosome forms around

Table 2 Correlation coefficients indicative of colocalizations

\section{BCL2L1 and BAX}

Hour of IVM $^{1} \quad$ Treatment $^{2}$

\begin{tabular}{llllll}
\hline 0 & & 0.77 & 0.77 & 0.31 & 0.32 \\
& & 0.88 & 0.86 & 0.16 & 0.17 \\
\hline 21 & 0.81 & 0.82 & 0.29 & 0.33 \\
\hline & TN & 0.75 & 0.67 & 0.28 & 0.34 \\
& TN & 0.82 & 0.84 & 0.35 & 0.47 \\
& TN & 0.76 & 0.76 & 0.16 & 0.26 \\
& HS & 0.76 & 0.77 & 0.29 & 0.36 \\
& HS & 0.74 & 0.76 & 0.21 & 0.26 \\
& HS & 0.76 & 0.76 & 0.47 & 0.53 \\
\hline & TN/TN & 0.72 & 0.71 & 0.31 & 0.34 \\
& TN/TN & 0.76 & 0.77 & 0.30 & 0.28 \\
& TN/TN & 0.74 & 0.76 & 0.36 & 0.39 \\
& HS/TN & 0.76 & 0.77 & 0.23 & 0.29 \\
& HS/TN & 0.74 & 0.76 & 0.38 & 0.45 \\
& HS/TN & 0.76 & 0.76 & 0.21 & 0.25 \\
\hline
\end{tabular}

\footnotetext{
${ }^{1}$ Pools of at least 30 oocytes were collected after 0,21 , or 42 hours of IVM (HS/TN).
}

${ }^{2}$ Oocytes experienced either TN throughout the entire IVM or HS during the first half of IVM (HS/TN).

${ }^{3}$ The PDC localization plugin in the Image J processing program was used to calculate Pearson's and Spearman's correlation coefficient representing colocalization of BCL2L1 with BAX or BECN1 in indivual oocytes. As per French et al. [48], a Pearson's R of 0.72 and Spearman's R of 0.63 is considered a high degree of colocalization. 

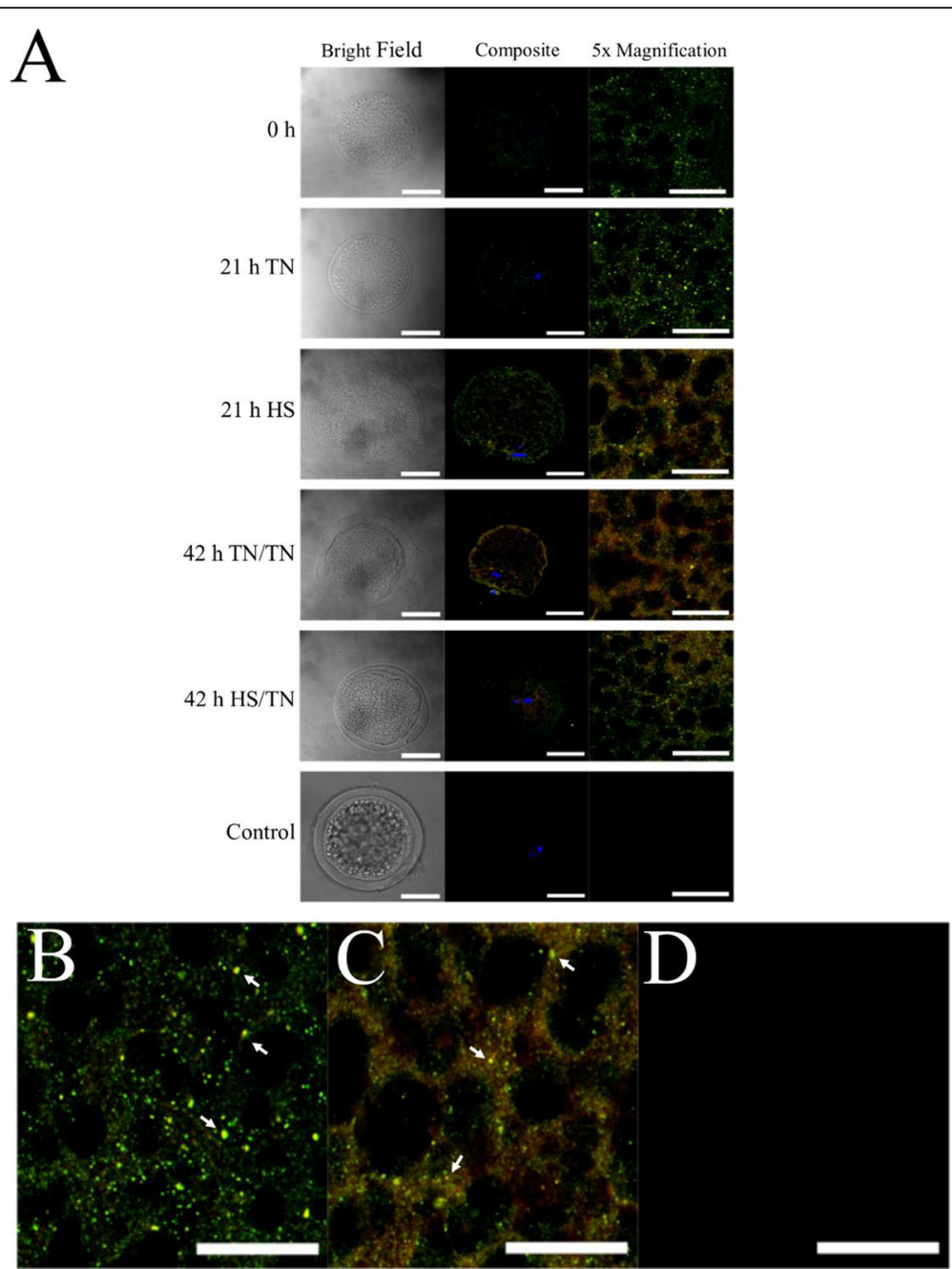

Fig. 3 Colocalization of BAX and BCL2L1. Oocytes that underwent either TN/TN IVM or HS/TN IVM were fixed and used for IHC to determine colocalization. Neither the time point during IVM nor the temperature treatment affected colocalization of antibody-labeled BCL2L1 and BAX in the oocyte. Based on level of fluorescence, there appeared to be a qualitative increase in BAX (red) at $21 \mathrm{~h}$ of IVM under HS compared to $21 \mathrm{~h}$ of IVM at TN conditions, though there appeared to be no effect on the abundance of BCL2L1 (green; $\mathbf{A}$ ). The comparison between 21-h TN (B), 21-h HS (C), or negative control (D) shows that there was punctate yellow signal representing colocalization in both TN and HS oocytes. For $\mathbf{A}$, the white bar in images in the left and middle columns represent $50 \mu \mathrm{m}$, and the white bar in images in the right column represents $20 \mu \mathrm{m}$. The white arrows point to areas of colocalization. The images in the right column are magnified $5 \times$ images from the same oocyte from the middle column

and sequesters damaged organelles or misfolded proteins, and proceeds to degrade its contents after interaction with a lysosome. BECN1 associates with PIK3C3 to increase nucleation of autophagosomes [19, 20], after which the autophagosome membrane is extended via two ubiquitin-like conjugation pathways including ATG12 or LC3. ATG12 forms a complex with ATG5 via an isopeptide bond, and this complex formation is indicative of increased autophagosome formation [21]. The cleavage of LC3-I to form LC3-II is indicative of autophagy occurrence, as cleavage of LC3-I and the conjugation of phosphatidylethanolamine allows for LC3-II to interact with the autophagosomal membrane $[24,52]$.
Whereas HS during IVM did not affect the abundance of BECN1 or BCL2L1 in MII oocytes, there was increased abundance of ATG12 in complex with ATG5 in MII oocytes after undergoing HS/TN IVM. This increase of ATG12-ATG5 complex formation suggests a rise in autophagosome formation [53], and this increase specifically as a result of HS during the first half of IVM could be due to HS being applied prior to transcriptional inactivation associated with germinal vesicle breakdown (GVBD). After GVBD, the oocyte is almost entirely transcriptionally quiescent [54], but oocytes that underwent the HS/TN temperature treatment during IVM experienced HS before GVBD at a time when a transcriptional response could have occurred. 

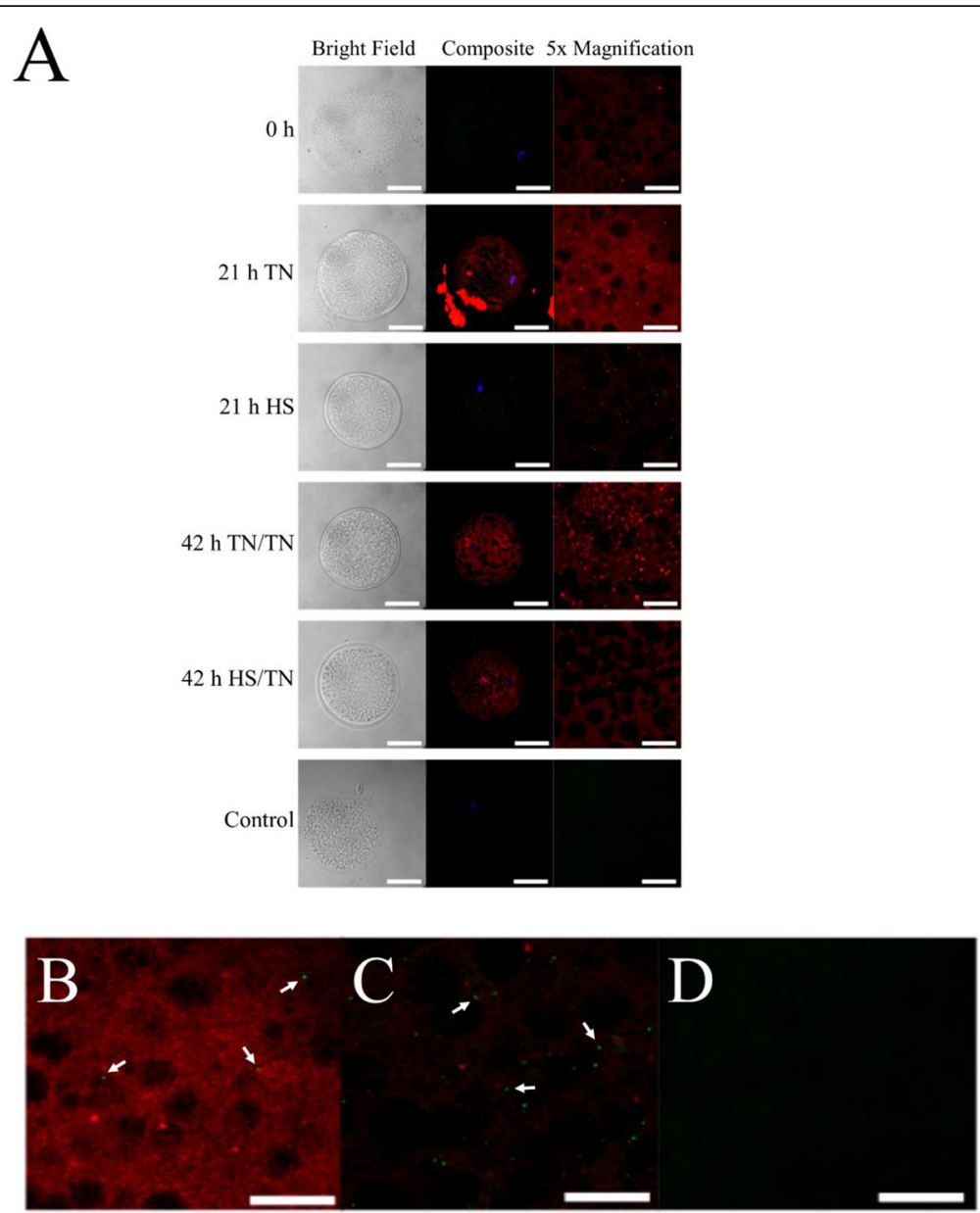

Fig. 4 Colocalization of BECN1 and BCL2L1. Oocytes that underwent either TN/TN IVM or HS/TN IVM were fixed and used for IHC to determine co-localization. Colocalization of BECN1 (green) and BCL2L1 (red) was low regardless of time point during IVM or temperature treatment. There appeared to be more punctate intense spots of BECN1 staining in oocytes having undergone $21 \mathrm{~h}$ of IVM under HS compared to the oocytes that underwent $21 \mathrm{~h}$ of IVM at TN conditions (A). The comparison between 21-h TN (B), 21-h HS (C), or negative control (D) shows that there was punctate green signal representing BECN1 but no colocalization in both TN and HS oocytes. For $\mathbf{A}$, the white bar in images in the left and middle columns represent $50 \mu \mathrm{m}$, and the white bar in images in the right column represents $20 \mu \mathrm{m}$. The white arrows point to areas of punctate BECN1 signal but no colocalization. The images in the right column are magnified $5 \times$ images from the same oocyte from the middle column

We have previously characterized the blastocyst development rate of MII oocytes collected after either TN/HS or HS/TN IVM, used for in vitro fertilization (IVF). Decreased blastocyst development rate was observed in fertilized TN/HS oocytes compared to controls, yet blastocyst development rate from fertilized HS/TN oocytes did not differ from control treated oocytes [50]. Therefore, we used the HS/TN temperature treatment for IVM to further characterize autophagy in oocytes under HS conditions because this treatment decreases maturation rate, but a subset of oocytes can reach MII arrest and maintain the ability to produce blastocysts.

At $21 \mathrm{~h}$ of IVM, there was decreased abundance of LC3B-II in oocytes that had undergone HS compared to oocytes that underwent IVM in TN conditions, suggesting that HS exacerbates the decrease in LC3B-II. A decrease in LC3B-II abundance during IVM could be interpreted as an increase in autophagosome utilization, since at least in some cell types, LC3B-II is degraded when autophagosomes interact with the lysosome [25]. This inverse relationship between decreased LC3B-II abundance and increased ATG12-ATG5 complex formation could be explained by the fact that the ATG12-ATG5 complex detaches from the autophagosomal membrane after autophagosome formation is complete [55].

Autophagy and apoptosis are regulated in tight coordination, partly through BCL-2 family member proteins, which are important regulators of apoptosis during mammalian ovary development [26-30]. The dual role of BCL-2 family members to regulate both autophagy and apoptosis is mediated by the ability of BCL-2 and BCL2L1 to prevent apoptosis by inhibiting the formation 


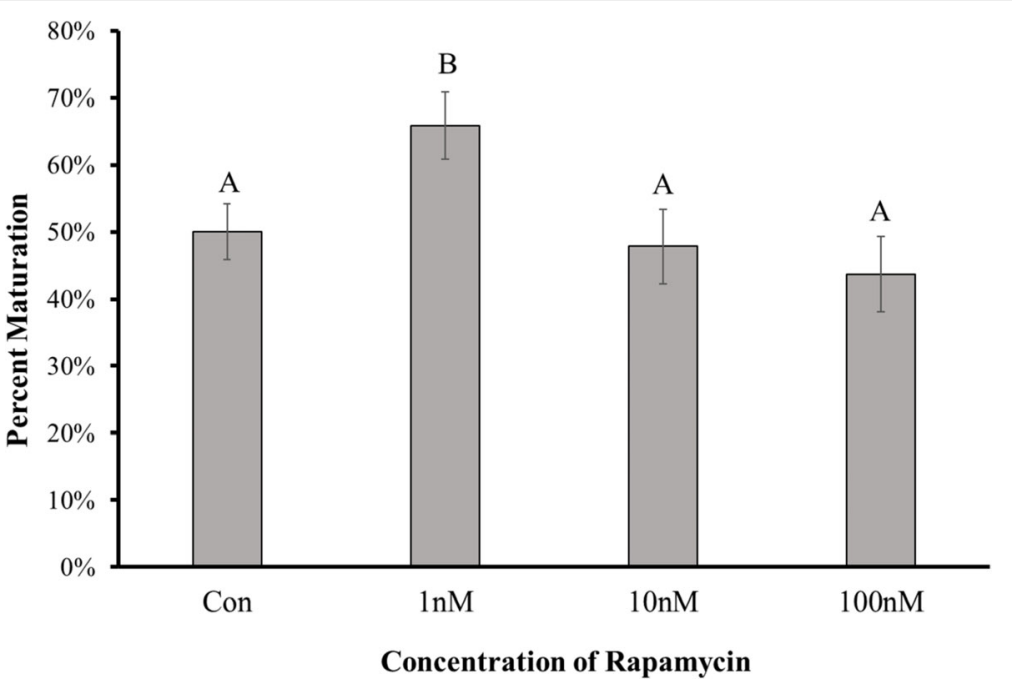

Fig. 5 Low Concentration of Rapamycin Increases Maturation Rate. Oocytes underwent IVM with the HS/TN temperature treatment in the presence of vehicle control, $100 \mathrm{nM}, 10 \mathrm{nM}$, or $1 \mathrm{nM}$ rapamycin. The inclusion of $100 \mathrm{nM}$ or $10 \mathrm{nM}$ rapamycin in the IVM media had no effect on maturation rate after HS/TN IVM compared to vehicle control, though oocytes matured in the presence of $1 \mathrm{nM}$ rapamycin had increased maturation rate compared to vehicle control

of mitochondrial pores that release cytochrome $\mathrm{C}$ [31], or BCL-2 and BCL2L1 can interact with BECN1 to inhibit autophagy [32, 33].

We have previously detected an increase in BCL2L1 protein abundance in the pig ovary due to HS, and immunostaining of sectioned ovarian tissue detected increased BCL2L1 localization in prophase I-arrested oocytes and primary follicles of ovaries from postpubertal gilts subjected to HS [43]. In this study the abundance of BCL2L1 in MII arrested oocytes after IVM was not affected by HS, suggesting increased BCL2L1 abundance in the oocyte is dependent on other biological contributors. The mechanisms regulated by BCL2L1 in an oocyte during maturation is potentially still affected by HS, as BCL2L1 regulates autophagy or apoptosis through protein-protein interactions [31, 32]. We therefore characterized colocalization of BCL2L1 with either BAX or BECN1 to determine if HS can affect BCL2L1 protein interactions.

Colocalization of BCL2L1 with BAX remained constant in oocytes regardless of time point of IVM or temperature treatment, although, based on relative fluorescence signal, there did appear to be a higher abundance of BAX in oocytes collected after $21 \mathrm{~h}$ of $\mathrm{HS}$ compared to TN oocytes. There was little to no colocalization of BECN1 with BCL2L1 in oocytes regardless of time point of IVM or temperature treatment, though HS appeared to induce more BECN1 protein. Based on the high degree of colocalization between BCL2L1 and BAX, as well as the fact this protein-protein interaction is well characterized in somatic cells [56], BCL2L1 may be inhibiting the release of cytochrome $\mathrm{C}$ in oocytes during
IVM regardless of TN or HS conditions. The distinct lack of colocalization between BCL2L1 and BECN1 indicates that BCL2L1 is not inhibiting autophagy under the IVM conditions used in this study. This finding, coupled with the fact that HS affects abundance of autophagyrelated proteins, suggests that HS is inducing autophagy in oocytes during maturation.

If autophagy has protective effects in terms of developmental competence on the oocyte, then artificially activating autophagy in oocytes undergoing HS should have a positive effect on meiotic maturation rate. Rapamycin induces autophagy in yeast [57] and mammalian cells [58], via the inhibition of mechanistic target of rapamycin (mTOR; formerly mammalian target of rapamycin) complex 1 (mTOC1). It is well characterized that mTOR is a central regulator of cellular metabolism and cell fate [59]. The mechanism of rapamycin inhibition of mTORC1 involves rapamycin forming a complex with FK506-binding protein (FKBP12), which binds directly to mTORC1 [60, 61]. While this mechanism is not completely understood, modeling of the rapamycin-FKBP12 complex bound to mTOR suggests rapamycin displaces the alignment of some mTORC1 substrates to the catalytic cleft $[59,62]$.

Autophagosome-like structures have been previously detected in oocytes and granulosa cells [42, 63, 64], and rapamycin inclusion in IVM media has beneficial effects in pig $[65,66]$ and bovine [67] oocytes. In this experiment, oocytes underwent IVM subjected to HS in the presence of rapamycin in the maturation media. The maturation rate of the oocytes in 10 or $100 \mathrm{nM}$ rapamycin was not different from oocytes that matured in the presence of vehicle control, however, the maturation rate of oocytes in $1 \mathrm{nM}$ rapamycin was 
increased compared to control. These results are similar to other experiments that characterize pig oocytes undergoing IVM in normal conditions in the presence of rapamycin [65]. Since mTOR is a major regulator of nutrient sensing and cell fate decision [59], there could be a threshold that exists where the negative effects of inhibition of mTORC1 outweigh the beneficial effects of autophagy induction. This threshold might explain why a low concentration of rapamycin increased the percentage of oocytes able to undergo IVM while higher concentrations did not. There could also be a threshold at which excessive induction of autophagy is detrimental to the oocyte, as autophagy and apoptosis regulation are tightly linked [56].

Embryonic development is dependent on oocyte competence, which is determined by the cytoplasmic contents of the oocyte [68, 69]. HS is associated with reduced oocyte developmental competence and embryonic development [7-9], and autophagy is a potential mechanism that the oocyte could utilize during HS to recycle damaged cellular components. Herein we demonstrate that HS affected autophagy-related proteins in maturing oocytes, and that pharmacological induction of autophagy increased oocyte maturation during HS.

\section{Conclusions}

The results presented here suggest that HS increases autophagy induction in pig oocytes during IVM, and that artificial induction of autophagy, using $1 \mathrm{nM}$ rapamycin, increases the maturation rate of oocytes during IVM. These data add to the understanding of the components of oocyte viability, which is necessary for improving the efficiency of assisted reproductive techniques and developing environmental stress mitigation strategies to improve reproduction $[70,71]$.

\section{Abbreviations \\ ATG: Autophagy related gene; BAX: BCL2 associated $\mathrm{X}$, apoptosis regulator; BCL2L1: BCL2 like 1 protein; BECN1: Beclin1; COC: Cumulus-oocyte-complex; HS: Heat stress; IVM: In vitro maturation; GV: Germinal vesicle-intact; GVBD: Germinal vesicle breakdown; LC3B: Microtubule-associated protein 1 light chain 3 beta; mTOR: Mechanistic target of rapamycin; PVA: Polyvinyl alcohol; TN: Thermal neutral}

\section{Supplementary information}

The online version contains supplementary material available at https://doi. org/10.1186/s12958-021-00791-4.

Additional file 1: Supplementary Fig. 1. Correlation predicting colocalization of BCL2L1 and interacting proteins. Oocytes that underwent either TN/TN IVM or HS/TN IVM were fixed and used for $\mathrm{HCC}$ to determine colocalization. The PDC colocalization plugin in the ImageJ processing program was used to calculate scatter plots representing colocalization of signal intensity collected from confocal microscopy of individual oocytes. Scatter plots representing colocalization of BCL2L1 (green) and BAX (red) signal suggest a high degree of colocalization based on overlapping signal $(\mathbf{A})$. Scatter plots representing colocalization of BECN1 (green) and BCL2L1 (red) signal suggest little to no

colocalization (B). Supplementary Fig. 2. Correlation comparison and relative fluorescence intensity. Oocytes that underwent either TN/TN or HS/TN IVM were fixed and used for IHC to determine colocalization ( $n=$ 3). The average Pearson's correlation coefficient was compared between $\mathrm{BCL} 2 \mathrm{~L} 1$ and BAX fluorescence colocalization and BCL2L1 and BECN1 fluorescence colocalization for each treatment $(\mathbf{A})$. The average relative fluorescence of $\mathrm{BAX}(\mathbf{B}), \mathrm{BC} 2 \mathrm{~L} 1(\mathbf{C})$, and BECN1 (D). Asterisks represents significant difference $(P<0.05)$ in the average correlation coefficient at each treatment per time point. Different superscripts denote significant difference $(P<0.05)$ between each treatment at each time point.

\section{Acknowledgements}

The authors would like to acknowledge Adrianne Kaiser for technical support, as well as other members of the Ross, Keating, and Baumgard research groups at lowa State University for their help with this project. Confocal microscopy was performed at the High Resolution Microscopy Facility of the lowa State University Office of Biotechnology.

\section{Authors' contributions}

$\mathrm{BJH}$ designed experiments, completed experiments, performed analysis and wrote the draft of the manuscript. MKA contributed to experimental design, execution of experiments, and edited the manuscript. YL contributed to experimental design, execution of experiments, and edited the manuscript. AFK and LHB contributed to the project funding, experimental design, and edited the manuscript. JWR contributed to experimental design, provided oversight of project and edited the manuscript. The author(s) read and approved the final manuscript.

\section{Funding}

This project was supported by the lowa Pork Producers Association and the Agriculture and Food Research Initiative Competitive Grant no. 2017-6701526459 from the USDA National Institute of Food and Agriculture.

Availability of data and materials

Not applicable.

\section{Declarations}

Ethics approval and consent to participate

All animal protocols in this project were approved by the lowa State University Animal Care and Use Committee.

\section{Consent for publication}

Not applicable.

\section{Competing interests}

Any opinion, findings, conclusions or recommendations expressed in this publication are those of the authors and do not necessarily reflect the view of the funding agency. No conflicts of interest, financial or otherwise are declared by the authors.

Received: 24 March 2021 Accepted: 23 June 2021 Published online: 09 July 2021

\section{References}

1. Bligh J. A theoretical consideration of the means whereby the mammalian core temperature is defended at a null zone. J Appl Physiol. 2006;100(4): 1332-7. https://doi.org/10.1152/japplphysiol.01068.2005.

2. Fuquay JW. Heat stress as it affects animal production. J Anim Sci. 1981; 52(1):164-74. https://doi.org/10.2527/jas1981.521164x.

3. Hansen PJ. Effects of heat stress on mammalian reproduction. Philos Trans $R$ Soc Lond Ser B Biol Sci. 2009;364(1534):3341-50. https://doi.org/10.1098/ rstb.2009.0131.

4. Ross JW, Hale BH, Gabler NK, Rhoads RP, Keating AF, Baumgard LH. Physiological consequences of heat stress in pigs. Anim Prod Sci. 2015; 55(12):1381-90. https://doi.org/10.1071/AN15267.

5. St-Pierre NR, Cobanov B, Schnitkey G. Economic Losses from Heat Stress by US Livestock Industries. J Diary Sci. 2003;86:E52-77.

6. Pollman D. Seasonal effects on sow herds: industry experience and management strategies. J Anim Sci. 2010;88:9-10 (Suppl. 3:9 (Abstr.)). 
7. Bertoldo M, Holyoake PK, Evans G, Grupen CG. Oocyte developmental competence is reduced in sows during the seasonal infertility period. Reprod Fertil Dev. 2010;22:1222-9.

8. Isom SC, Prather RS, Rucker EB 3rd. Heat stress-induced apoptosis in porcine in vitro fertilized and parthenogenetic preimplantation-stage embryos. Mol Reprod Dev. 2007;74(5):574-81. https://doi.org/10.1002/mrd.20620.

9. Pennarossa G, Maffei S, Rahman MM, Berruti G, Brevini TA, Gandolfi F, Characterization of the constitutive pig ovary heat shock chaperone machinery and its response to acute thermal stress or to seasonal variations. Biol Reprod. 2012;87:119.

10. Nishio K, Yamazaki M, Taniguchi M, Besshi K, Morita F, Kunihara T, et al. Sensitivity of the meiotic stage to hyperthermia during in vitro maturation of porcine oocytes. Acta Vet Hung. 2017;65(1):115-23. https://doi.org/10.1 556/004.2017.012.

11. Roth Z, Hansen PJ. Disruption of nuclear maturation and rearrangement of cytoskeletal elements in bovine oocytes exposed to heat shock during maturation. Reproduction. 2005;129(2):235-44. https://doi.org/10.1530/rep.1. 00394.

12. Campen KA, Abbott CR, Rispoli LA, Payton RR, Saxton AM, Edwards JL. Heat stress impairs gap junction communication and cumulus function of bovine oocytes. J Reprod Dev. 2018;64(5):385-92. https://doi.org/10.1262/jrd.2018-029.

13. Yin C, Liu J, He B, Jia L, Gong Y, Guo H, et al. Heat stress induces distinct responses in porcine cumulus cells and oocytes associated with disrupted gap junction and trans-zonal projection colocalization. J Cell Physiol. 2019; 234(4):4787-98. https://doi.org/10.1002/jcp.27277.

14. Klionsky DJ. The molecular machinery of autophagy: unanswered questions. J Cell Sci. 2005;118(Pt 1):7-18. https://doi.org/10.1242/jcs.01620.

15. Klionsky DJ, Emr SD. Autophagy as a regulated pathway of cellular degradation. Science. 2000;290(5497):1717-21. https://doi.org/10.1126/ science.290.5497.1717.

16. Pyo JO, Nah J, Jung YK. Molecules and their functions in autophagy. Exp Mol Med. 2012;44(2):73-80. https://doi.org/10.3858/emm.2012.44.2.029.

17. Mizushima N. The role of the Atg1/ULK1 complex in autophagy regulation. Curr Opin Cell Biol. 2010;22(2):132-9. https://doi.org/10.1016/ j.ceb.2009.12.004.

18. Mizushima N, Yoshimori T, Ohsumi Y. The role of Atg proteins in autophagosome formation. Annu Rev Cell Dev Biol. 2011;27(1):107-32 https://doi.org/10.1146/annurev-cellbio-092910-154005.

19. Kang R, Zeh HJ, Lotze MT, Tang D. The Beclin 1 network regulates autophagy and apoptosis. Cell Death Differ. 2011;18(4):571-80. https://doi. org/10.1038/cdd.2010.191.

20. Kihara A, Kabeya Y, Ohsumi Y, Yoshimori T. Beclin-phosphatidylinositol 3kinase complex functions at the trans-Golgi network. EMBO Rep. 2001;2(4): 330-5. https://doi.org/10.1093/embo-reports/kve061.

21. Geng J, Klionsky DJ. The Atg8 and Atg12 ubiquitin-like conjugation systems in macroautophagy. 'Protein modifications: beyond the usual suspects' review series. EMBO Rep. 2008;9(9):859-64. https://doi.org/10.1038/embor.2 008.163 .

22. Mizushima N, Noda T, Yoshimori T, Tanaka Y, Ishii T, George MD, et al. A protein conjugation system essential for autophagy. Nature. 1998;395(6700): 395-8. https://doi.org/10.1038/26506.

23. Taherbhoy AM, Tait SW, Kaiser SE, Williams AH, Deng A, Nourse A, et al. Atg8 transfer from Atg7 to Atg3: a distinctive E1-E2 architecture and mechanism in the autophagy pathway. Mol Cell. 2011;44(3):451-61. https:// doi.org/10.1016/j.molcel.2011.08.034

24. Martinet W, De Meyer GR, Andries L, Herman AG, Kockx MM. In situ detection of starvation-induced autophagy. J Histochem Cytochem. 2006; 54(1):85-96. https://doi.org/10.1369/jhc.5A6743.2005.

25. Tanida I, Minematsu-keguchi N, Ueno T, Kominami E. Lysosomal turnover, but not a cellular level, of endogenous LC3 is a marker for autophagy. Autophagy. 2005;1(2):84-91. https://doi.org/10.4161/auto.1.2.1697.

26. Ratts VS, Flaws JA, Kolp R, Sorenson CM, Tilly JL. Ablation of bcl-2 gene expression decreases the numbers of oocytes and primordial follicles established in the post-natal female mouse gonad. Endocrinology. 1995; 136(8):3665-8. https://doi.org/10.1210/endo.136.8.7628407.

27. Hsu SY, Lai RJ, Finegold M, Hsueh AJ. Targeted overexpression of Bcl-2 in ovaries of transgenic mice leads to decreased follicle apoptosis, enhanced folliculogenesis, and increased germ cell tumorigenesis. Endocrinology. 1996;137(11):4837-43. https://doi.org/10.1210/endo.137.11.8895354.

28. Basavarajappa MS, Karman BN, Wang W, Gupta RK, Flaws JA. Methoxychlor induces atresia by altering $\mathrm{BCl} 2$ factors and inducing caspase activity in mouse ovarian antral follicles in vitro. Reprod Toxicol (Elmsford, NY). 2012; 34(4):545-51.

29. Perez GI, Robles R, Knudson CM, Flaws JA, Korsmeyer SJ, Tilly JL. Prolongation of ovarian lifespan into advanced chronological age by Baxdeficiency. Nat Genet. 1999;21(2):200-3. https://doi.org/10.1038/5985.

30. Tanner EA, Blute TA, Brachmann CB, McCall K. BCl-2 proteins and autophagy regulate mitochondrial dynamics during programmed cell death in the Drosophila ovary. Development (Cambridge, England). 2011;138(2):327-38.

31. Moldoveanu T, Follis AV, Kriwacki RW, Green DR. Many players in BCL-2 family affairs. Trends Biochem Sci. 2014;39(3):101-11. https://doi.org/10.101 6/j.tibs.2013.12.006.

32. Maiuri MC, Le Toumelin G, Criollo A, Rain JC, Gautier F, Juin P, et al. Functional and physical interaction between $\mathrm{BCl}-\mathrm{X}(\mathrm{L})$ and a $\mathrm{BH} 3$-like domain in Beclin-1. EMBO J. 2007;26(10):2527-39. https://doi.org/10.1038/sj.emboj. 7601689.

33. Pattingre S, Tassa A, Qu X, Garuti R, Liang XH, Mizushima N, et al. Bcl-2 antiapoptotic proteins inhibit Beclin 1-dependent autophagy. Cell. 2005;122: 927-39.

34. Cecconi F, Piacentini M, Fimia GM. The involvement of cell death and survival in neural tube defects: a distinct role for apoptosis and autophagy? Cell Death Differ. 2008;15(7):1170-7. https://doi.org/10.1038/cdd.2008.64.

35. Fimia GM, Stoykova A, Romagnoli A, Giunta L, Di Bartolomeo S, Nardacci R, et al. Ambra1 regulates autophagy and development of the nervous system. Nature. 2007;447(7148):1121-5. https://doi.org/10.1038/nature05925.

36. Qu X, Zou Z, Sun Q, Luby-Phelps K, Cheng P, Hogan RN, et al. Autophagy gene-dependent clearance of apoptotic cells during embryonic development. Cell. 2007;128(5):931-46. https://doi.org/10.1016/j.cell.2006.12.044.

37. Zeng $\mathrm{X}$, Overmeyer $\mathrm{JH}$, Maltese WA. Functional specificity of the mammalian Beclin-Vps34 PI 3-kinase complex in macroautophagy versus endocytosis and lysosomal enzyme trafficking. J Cell Sci. 2006;119(Pt 2):25970. https://doi.org/10.1242/jcs.02735.

38. Adastra KL, Chi MM, Riley JK, Moley KH. A differential autophagic response to hyperglycemia in the developing murine embryo. Reproduction. 2011; 141(5):607-15. https://doi.org/10.1530/REP-10-0265.

39. Xu YN, Cui XS, Sun SC, Lee SE, Li YH, Kwon JS, et al. Mitochondria dysfunction influences apoptosis and autophagy in porcine parthenotes developing in vitro. J Reprod Dev. 2011;57(1):143-50. https://doi.org/10.12 62/jrd.10-110H.

40. Tsukamoto S, Kuma A, Murakami M, Kishi C, Yamamoto A, Mizushima N Autophagy is essential for preimplantation development of mouse embryos. Science. 2008;321(5885):117-20. https://doi.org/10.1126/science.11 54822.

41. Lee S, Hiradate Y, Hoshino Y, Tanemura K, Sato E. Quantitative analysis in LC3-II protein in vitro maturation of porcine oocyte. Zygote. 2013;22(3):1-7.

42. De Felici M, Lobascio AM, Klinger FG. Cell death in fetal oocytes: many players for multiple pathways. Autophagy. 2008;4(2):240-2. https://doi.org/1 0.4161 /auto. 5410

43. Hale BJ, Hager CL, Seibert JT, Selsby JT, Baumgard LH, Keating LH, et al. Heat Stress Induces Autophagy in Pig Ovaries during Follicular Development. Biol Reprod. 2017;93(3):426-37.

44. Yang CX, Du ZQ, Wright EC, Rothschild MF, Prather RS, Ross JW. Small RNA Profile of the Cumulus Oocyte Complex and Early Embryos in the Pig. Biol Reprod. 2012; 87(5):117.

45. Zhao J, Ross JW, Hao Y, Spate LD, Walters EM, Samuel MS, et al. Significant Improvement in Cloning Efficiency of an Inbred Miniature Pig by Histone Deacetylase Inhibitor Treatment After Somatic Cell Nuclear Transfer. Biol Reprod. 2009; 81(3):525-30.

46. Yang $C X$, Wright EC, Ross JW. Expression of RNA-binding proteins DND1 and FXR1 in the porcine ovary, and during oocyte maturation and early embryo development. Mol Reprod Dev. 2012;79(8):541-52. https://doi.org/1 $0.1002 / \mathrm{mrd} .22059$

47. Martin C, Beaujean N, Brochard V, Audouard C, Zink D, Debey P. Genome restructuring in mouse embryos during reprogramming and early development. Dev Biol. 2006;292(2):317-32. https://doi.org/10.1016/j.ydbio.2 006.01.009.

48. French AP, Mills S, Swarup R, Bennett MJ, Pridmore TP. Colocalization of fluorescent markers in confocal microscope images of plant cells. Nat Protoc. 2008;3(4):619-28. https://doi.org/10.1038/nprot.2008.31.

49. Schneider CA, Rasband WS, Eliceiri KW. NIH image to ImageJ: 25 years of image analysis. Nat Methods. 2012;9(7):671-5. https://doi.org/10.1038/ nmeth.2089. 
50. Wright E, Yang CX, Scanlon R, Tuggle CK, Ross JW. Development of an in vitro heat stress model for pig oocyte maturation. In: Zinn SA, Shanks R, editors. American Society of Animal Science Midwest Section Meeting. Des Moines: Oxford Unveristy Press; 2012;45:17.

51. Zhang J. Teaching the basics of autophagy and mitophagy to redox biologists--mechanisms and experimental approaches. Redox Biol. 2015;4: 242-59. https://doi.org/10.1016/j.redox.2015.01.003.

52. Kabeya Y, Mizushima N, Ueno T, Yamamoto A, Kirisako T, Noda T, et al. LC3, a mammalian homologue of yeast Apg8p, is localized in autophagosome membranes after processing. EMBO J. 2000;19(21):5720-8. https://doi.org/1 0.1093/emboj/19.21.5720

53. Kuma A, Mizushima N, Ishihara N, Ohsumi Y. Formation of the approximately 350-kDa Apg12-Apg5.Apg16 multimeric complex, mediated by Apg16 oligomerization, is essential for autophagy in yeast. J Biol Chem. 2002;277(21):18619-25. https://doi.org/10.1074/jbc.M111889200.

54. De La Fuente R, Viveiros MM, Burns KH, Adashi EY, Matzuk MM, Eppig J. Major chromatin remodeling in the germinal vesicle (GV) of mammalian oocytes is dispensable for global transcriptional silencing but required for centromeric heterochromatin function. Dev Biol. 2004;275(2):447-58. https:// doi.org/10.1016/j.ydbio.2004.08.028.

55. Mizushima N, Yamamoto A, Hatano M, Kobayashi Y, Kabeya Y, Suzuki K, et al. Dissection of autophagosome formation using Apg5-deficient mouse embryonic stem cells. J Cell Biol. 2001;152(4):657-68. https://doi.org/10.1 083/jcb.152.4.657.

56. Mukhopadhyay S, Panda PK, Sinha N, Das DN, Bhutia SK. Autophagy and apoptosis: where do they meet? Apoptosis. 2014;19(4):555-66. https://doi. org/10.1007/s10495-014-0967-2.

57. Noda T, Ohsumi Y. Tor, a phosphatidylinositol kinase homologue, controls autophagy in yeast. J Biol Chem. 1998;273(7):3963-6. https://doi.org/10.1 074/jbc.273.7.3963.

58. Blommaart EF, Luiken JJ, Blommaart PJ, van Woerkom GM, Meijer AJ. Phosphorylation of ribosomal protein $\mathrm{S} 6$ is inhibitory for autophagy in isolated rat hepatocytes. J Biol Chem. 1995;270(5):2320-6. https://doi.org/1 0.1074 /jbc.270.5.2320.

59. Shimobayashi M, Hall MN. Making new contacts: the mTOR network in metabolism and signalling crosstalk. Nat Rev Mol Cell Biol. 2014;15(3):15562. https://doi.org/10.1038/nrm3757.

60. Brown EJ, Albers MW, Shin TB, Ichikawa K, Keith CT, Lane WS, et al. A mammalian protein targeted by G1-arresting rapamycin-receptor complex. Nature. 1994;369(6483):756-8. https://doi.org/10.1038/369756a0.

61. Sabatini DM, Erdjument-Bromage H, Lui M, Tempst P, Snyder SH. RAFT1: a mammalian protein that binds to FKBP12 in a rapamycin-dependent fashion and is homologous to yeast TORs. Cell. 1994;78(1):35-43. https://doi. org/10.1016/0092-8674(94)90570-3.

62. Yang H, Rudge DG, Koos JD, Vaidialingam B, Yang HJ, Pavletich NP. mTOR kinase structure, mechanism and regulation. Nature. 2013;497(7448):217-23. https://doi.org/10.1038/nature12122.

63. Lobascio AM, Klinger FG, Scaldaferri ML, Farini D, De Felici M. Analysis of programmed cell death in mouse fetal oocytes. Reproduction (Cambridge, England). 2007;134(2):241.

64. Gannon AM, Stampfli MR, Foster WG. Cigarette smoke exposure leads to follicle loss via an alternative ovarian cell death pathway in a mouse model. Toxicol Sci. 2012;125(1):274-84. https://doi.org/10.1093/toxsci/kfr279.

65. Song BS, Kim JS, Kim YH, Sim BW, Yoon SB, Cha JJ, et al. Induction of autophagy during in vitro maturation improves the nuclear and cytoplasmic maturation of porcine oocytes. Reprod Fertil Dev. 2014;26(7):974-81. https:// doi.org/10.1071/RD13106.

66. Lee J, Park Jl, Yun Jl, Lee Y, Yong H, Lee ST, et al. Rapamycin treatment during in vitro maturation of oocytes improves embryonic development after parthenogenesis and somatic cell nuclear transfer in pigs. J Vet Sci. 2015;16(3):373-80. https://doi.org/10.4142/jvs.2015.16.3.373.

67. Song BS, Yoon SB, Kim JS, Sim BW, Kim YH, Cha JJ, et al. Induction of autophagy promotes preattachment development of bovine embryos by reducing endoplasmic reticulum stress. Biol Reprod. 2012;87(1):8 1-11.

68. Krisher RL, Bavister BD. Responses of oocytes and embryos to the culture environment. Theriogenology. 1998;49(1):103-14. https://doi.org/10.1016/ S0093-691X(97)00405-6.

69. Gosden RG. Oogenesis as a foundation for embryogenesis. Mol Cell Endocrinol. 2002;186(2):149-53. https://doi.org/10.1016/S0303-7207(01 00683-9.
70. Jurema MW, Nogueira D. In vitro maturation of human oocytes for assisted reproduction. Fertil Steril. 2006:86(5):1277-91. https://doi.org/10.1016/j. fertnstert.2006.02.126.

71. Whyte JJ, Prather RS. Genetic modifications of pigs for medicine and agriculture. Mol Reprod Dev. 2011;78(10-11):879-91. https://doi.org/10.1002/ mrd.21333.

\section{Publisher's Note}

Springer Nature remains neutral with regard to jurisdictional claims in published maps and institutional affiliations.

\section{Ready to submit your research? Choose BMC and benefit from:}

- fast, convenient online submission

- thorough peer review by experienced researchers in your field

- rapid publication on acceptance

- support for research data, including large and complex data types

- gold Open Access which fosters wider collaboration and increased citations

- maximum visibility for your research: over $100 \mathrm{M}$ website views per year

At BMC, research is always in progress.

Learn more biomedcentral.com/submissions 